\title{
LEITURA CUMULATIVA COMO LETRAMENTO LITERÁRIO
}

\section{CUMULATIVE READING AS LITERARY LITERACY}

\author{
https://doi.org/10.20873/uft2179-3948.2020v11n3p205-216
}

Rildo Cosson ${ }^{1}$

Resumo: Embora o letramento literário comece antes e continue depois da escola, em um processo contínuo e permanente, é na escola que se torna, por meio da formação do leitor literário, objetivo de ensino explícito e sistemático. Para tanto, concorrem várias estratégias didáticas, inclusive a Leitura Cumulativa, que se destaca por sua versatilidade, podendo contemplar tanto o aluno individualmente em leitura extensiva, quanto uma turma em leitura intensiva. Nesse estudo, apresentamos a fundamentação teórica e metodológica dessa prática de letramento literário na escola e um exemplo de sua aplicação a partir da experiência de professores em curso de formação em serviço.

Palavras-chave: ensino de literatura; leitor literário; prática de leitura literária; letramento literário.

Abstract: Although literary literacy begins before and continues after school, it is there that it becomes, by the means of a literary reader development, a clear and regular learning goal. For that, may be used. One of the possible pedagogical approaches Cumulative Reading, that stands out for its versatility and may be used both for extensive reading of an individual student, as well as intensive reading practice of a class. This study presents the theoretical and methodological basis of literary literacy use at school and an example derived from the experience of teachers in an in-service training course.

Keywords: the teaching of literature; literary reader; practice of literary reading; literary literacy.

\section{Introdução}

No capítulo de abertura de Uma história da leitura, Alberto Manguel destaca duas descobertas que fazem parte da formação da maioria dos leitores literários. A primeira delas é que "ler é cumulativo e avança em progressão geométrica: cada leitura nova baseia-se no que o leitor leu antes" (MANGUEL, 1997, p. 33). Esse princípio, que também está na base da intertextualidade compreendida como o diálogo entre textos, reconhecido naquele texto a partir da memória do leitor ${ }^{2}$, é ilustrado pelo autor em um

${ }^{1}$ Professor do Programa de Pós-Graduação em Letras da UFPB, doutor em Letras (UFRGS) e Educação (UFMG), mestre em Teoria da Literatura (UnB) - rcosson@gmail.com

${ }^{2}$ A relação entre história do leitor e intertextualidade é claramente exposta por Linda Hutcheon, quando, tratando das diferenças entre paródia e intertextualidade, indaga: "O diálogo intertextual não é, antes, um 
caleidoscópio de citações que constitui o seu vasto repertório de leituras. Todavia, quando chamada a atenção, todo leitor literário consegue perceber sem grandes dificuldades que a leitura de um novo texto sempre é contextualizada pelos outros textos anteriormente lidos. Antes mesmo da primeira página, os textos já lidos nos indicam os caminhos a percorrer no texto desconhecido, funcionando tanto como critério de seleção quanto como estratégia de predição dos conteúdos e de enquadramento genérico do texto. No desenrolar da leitura, eles nos acompanham fornecendo associações diversas, que nos ajudam a compreender melhor certas passagens e interpretar outras. Ao final, quando fechamos a última página, os textos anteriores se ajustam para abrir espaço em nosso repertório ao texto que acabou de ser lido. É esse movimento de círculos em espiral progressivamente mais largos e mais densos que faz da leitura literária um processo essencialmente cumulativo, como se pode inferir de diferentes teorias e modelos que buscam explicitar o seu funcionamento (SCHOLES, 1991; ROSENBLATT, 1994; SOLÉ, 1998).

A segunda descoberta é que essa acumulação - que é a verdadeira responsável pela história de leitura daquele leitor - nunca é linear. Nas palavras de Manguel:

Tal como o próprio ato de ler, uma história da leitura salta para a frente até o nosso tempo - até mim, até minha experiência como leitor - e depois volta a uma página antiga em um século estrangeiro e distante. Ela salta capítulos, folheia, seleciona, relê, recusa-se a seguir uma ordem convencional. (MANGUEL, 1997, p. 37).

Por isso, dificilmente a formação do leitor literário cabe no ordenamento estreito das histórias da literatura tradicionalmente ensinadas na escola, pois elas seguem uma linha temporal única (OLIVEIRA, 2008). Nem mesmo nos arranjos determinados por idade, formais ou temáticos, aos quais as crianças e os adolescentes costumam ser submetidos no ensino da literatura (AZEVEDO, 2003), uma vez que eles mais constrangem do que impulsionam o processo cumulativo da leitura. Não que essas e outras formas de organizar o saber literário sejam inúteis ou dispensáveis para quem ensina. Ao contrário, elas devem ser de conhecimento do professor porque se constituem em pontos de referência, tal como as placas de sinalização em uma estrada, para o caminho que deve construir junto com seus alunos para a formação do leitor literário.

diálogo entre o leitor e a sua memória de outros textos, conforme são evocados pelo texto em questão?" (HUTCHEON, 1989, p. 111). 
Esse caminho, para continuar com a metáfora, passa pela liberdade do leitor de compor seu repertório, porém essa liberdade não pode ser confundida com o laissez-faire do ler por ler, como se os textos brotassem espontaneamente de um lugar inefável e a leitura literária implicasse apenas a simples aprendizagem da decifração de signos. Antes, pressupõe, até por ser caminho, uma direção clara a ser seguida, uma sistematização apoiada em princípios teóricos e metodológicos que possibilitam fazer da acumulação de leituras um meio para a formação do leitor literário.

Em nossa perspectiva, o letramento literário, enquanto processo de apropriação literária dos textos literários (COSSON; PAULINO, 2009), cumpre melhor esse papel porque é uma construção que se faz individual e coletivamente dentro de uma comunidade de leitores. Na escola, essa comunidade de leitores é representada pela turma e pelo professor que compreende que seus alunos iniciaram o percurso de formação literária previamente, ou seja, eles já trazem para a sala de aula um repertório literário construído com sua família e outros contextos de socialização. Logo é a partir desse repertório, o qual abarca tanto os textos quanto os modos de ler esses textos (EVEN-ZOHAR, 2017), que a comunidade se estabelece e o processo de formação escolar do leitor literário se desenvolve.

Nesse processo, é preciso considerar, ainda, que o leitor literário sempre realiza dois percursos de aprendizagem: um interno, em direção a si mesmo, que leva ao autoconhecimento, e outro externo, em direção ao mundo, pelo qual ele experiencia a força da linguagem literária. Ao professor, como leitor experiente, cabe orientar, conduzir e ordenar, sem ignorar as peculiaridades de cada aluno, as leituras da turma para que elas possam cumprir essa dupla função. Para tanto, deve considerar, por um lado, que os textos literários apresentam diferentes níveis de complexidade em sua elaboração e recepção, logo deve priorizar a seleção de textos diversos e plurais para serem lidos em sala de aula. Por outro lado, que toda leitura implica resposta, porque "ler consiste em produzir sentidos por meio de um diálogo, um diálogo que travamos com o passado enquanto experiência do outro, experiência que compartilhamos e pela qual nos inserimos em uma determinada comunidade de leitores" (COSSON, 2014, p. 36).

Obviamente, esses aspectos ligados à leitura cumulativa não são os únicos a serem considerados quando se trata da formação do leitor literário, mas refletir e adotar como princípios o que expomos acima já seria um grande passo na sistematização do letramento literário na escola. Para demonstrar concretamente como o letramento literário pode ser 
efetivado na escola, temos sugeridos diversas estratégias didáticas em outros estudos (COSSON, 2006; 2014). Aqui escolhemos apresentar uma prática de sala de aula que

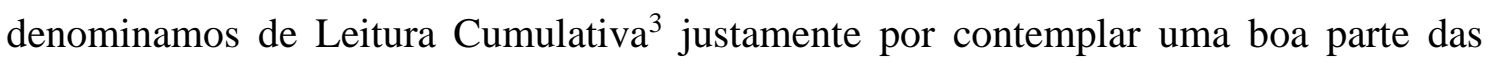
questões que discutimos anteriormente. São os passos dessa prática que explicitaremos nos dois tópicos a seguir: o primeiro dedicado a detalhar o funcionamento da Leitura Cumulativa e o segundo a exemplificar esse funcionamento a /partir de uma experiência realizada com professores em curso de formação em serviço.

\section{A prática da Leitura Cumulativa}

Quando falamos de práticas de letramento literário, estamos nos referindo tanto ao conceito de prática como é empregado nos novos estudos de letramento (STREET, 2003), quanto às dinâmicas de sala de aula, sequências didáticas, unidade de ensino, oficina pedagógica ou qualquer outra denominação dada a atividades integradas de leitura e escrita de textos literários no âmbito escolar. Nesse último caso, preferimos o termo "prática" a seus concorrentes genéricos porque com ele se enfatiza que essas ações pedagógicas precisam ser efetivamente executadas, ou seja, trata-se do aprender a fazer fazendo. Também é um termo adequado porque pressupõe o manuseio direto dos textos literários pelos alunos, que é essencial para o processo de apropriação do letramento literário. Além disso, sugere, pelo aprender fazendo e manuseio efetivo dos textos literários, que se trata de uma aprendizagem ativa, uma experiência que demanda o envolvimento emocional, cognitivo e físico do aluno.

Como em qualquer outra prática de letramento literário, o planejamento e execução da Leitura Cumulativa precisam seguir determinados pressupostos para serem bem-sucedidos. O primeiro deles é que os textos a serem selecionados para a atividade devem ser duplamente relevantes, ou seja, devem atender tanto às características da prática quanto às necessidades dos alunos. Trata-se de buscar textos capazes de equilibrar os objetivos de ensino do professor com os interesses dos alunos que estão em processo da aprendizagem. Para essa seleção, conta tanto o repertório do professor quanto o dos alunos. O repertório do professor funciona como uma fonte de referências, e o dos alunos

\footnotetext{
${ }^{3}$ Diferentemente do nosso emprego, a expressão "leitura cumulativa" é usada em Portugal nos inquéritos sobre hábitos de leitura para designar um dos três tipos de leitura pesquisados, que é aquela que se vale recorrentemente de livros, jornais e revistas, sendo a "leitura parcelar" e a "não-leitura" os outros dois tipos que se referem a uma leitura pouco frequente e de apenas dois ou um dos suportes e ausência de leitura, respectivamente (FREITAS; SANTOS, 1992).
} 
como parâmetro não só para a execução daquela prática específica, mas também para o objetivo maior e permanente de desenvolver a competência literária na escola (NIKOLAJEVA, 2010; WITTE; RIJLAARSDAM ;SCHRAM, 2012).

Um segundo pressuposto é que os alunos devem ser preparados para a prática, o que significa que a prática em si mesma, a leitura e escrita dos textos literários que são alvo da prática, deve ser precedida de uma motivação, um aquecimento, uma introdução que encaminhe os alunos na direção pretendida pela prática. Essa atividade, que naturalmente precisa se ajustar ao que virá a seguir, não pode ser longa e funciona melhor quando envolve algum registro, preferencialmente escrito para alunos maiores. Observese, ainda, que não se trata da simples apresentação do texto literário como normalmente acontece nas salas de aula, mas, sim, uma atividade curta e prévia a essa apresentação. A razão de sua existência é despertar a atenção, focalizar e sensibilizar o aluno para a leitura literária que virá a seguir.

Um terceiro pressuposto é que a leitura dos textos literários deve ser precedida ou acompanhada ou imediatamente seguida de anotações escritas ou algum outro tipo de registro. O objetivo desse registro é manter para o leitor a memória de seu encontro inicial com o texto, podendo, assim, servir de base e contraste para leituras posteriores. Por essa razão, as anotações feitas durante a leitura são as mais relevantes, mas aquelas que são feitas imediatamente antes ou depois também oferecem ganhos para a compreensão quanto ao modo como o leitor aborda o texto literário e reage à sua leitura. Em muitos casos, esse registro é um dos passos da prática ou até constitui a sua ação básica, a exemplo dos diários de leitura.

Um quarto pressuposto é que o leitor deve interpretar o texto a partir de seus conhecimentos e experiência. Nesse caso, o que se busca enfatizar é que a interpretação que conta em uma prática de letramento literário é aquela que o aluno faz com seus recursos de leitor, e não aquela feita pelo professor, o crítico ou qualquer outro leitor que seja supostamente autorizado a dizer qual é o sentido do texto. Com isso não se está defendendo que a leitura feita pelo aluno não possa ser desenvolvida, discutida e avaliada, mas, sim, que a interpretação deve partir de dentro para fora, seguindo um percurso que começa no aluno, passa por outros leitores e volta para o aluno em um movimento de ampliação e aprofundamento. Esse movimento, que é a razão de ser da prática, não prescinde, nem objetiva substituir a leitura inicial. Antes, procura agregar a ela outros aspectos e sentidos, podendo modificar ou reafirmar essa leitura inicial, sendo que ambos 
os resultados - e todas as nuances que existem entre eles - são igualmente positivos para o letramento literário.

O quinto pressuposto é que a leitura e escrita dos textos literários deve ser compartilhada com outros leitores. Na escola, esses leitores são naturalmente os alunos de uma turma, ainda que o compartilhamento possa ser alargado para a família, a escola como um todo e até a leitores externos mais distanciados, a depender dos mecanismos de compartilhamento inseridos na prática. Dessa forma, o compartilhamento pode começar em uma dupla, passar por grupo pequeno de três a cinco alunos, atingir a turma em plenária e daí atingir outros públicos. Também pode fazer um percurso diverso, iniciando por uma atividade coletiva, como a discussão de uma peça de teatro ou um filme que todos assistiram juntos, e a partir dela outros compartilhamentos mais restritos serem implementados. Aqui, o que realmente importa na prática não é ordem, nem os tipos de compartilhamento e, sim, que haja um ou mais momentos em que a leitura dos alunos seja tornada pública, no sentido de apresentada e discutida em uma determinada comunidade.

No conjunto das práticas de letramento literário na escola, a prática da Leitura Cumulativa é uma das mais versáteis porque pode contemplar tanto o aluno individualmente em leitura extensiva, quanto uma turma em leitura intensiva, assim como ser uma atividade que pode ser realizada em poucas aulas, um bimestre, um semestre e até um ano inteiro. Em qualquer de suas versões, ela consiste basicamente na leitura sucessiva de uma coletânea de textos intertextualizados, com retorno ao primeiro texto, isso a cada leitura do texto seguinte, de um determinado número de textos ou ao final da coletânea.

O ponto chave da Leitura Cumulativa é a organização da coletânea que requer sensibilidade e conhecimento para reunir textos que possam ser intertextualmente relacionados pelos alunos. Essa operação intertextual é bastante livre porque não precisa se basear em referências e citações explícitas entre os textos, uma vez que se trata de fato de uma construção presumida de intertextualidade, e não da intertextualidade em si mesma. Também não deve ser de cunho exclusivamente temático, mas contemplar aspectos formais do texto e outros elementos que ajudem a desenvolver a competência literária do aluno. Por isso é importante que os textos sejam plurais e diversificados tanto pela profundidade com que o tema é abordado quanto pela complexidade de elaboração da linguagem literária. 
Selecionados os textos, passa-se para a execução da prática que, como já vimos, é antecedida por uma breve preparação para a apresentação do primeiro texto. A partir da leitura do primeiro, os outros textos vão se seguindo em cadeia, com registro das leituras tendo como referência o primeiro texto. Aqui, é importante que o professor afaste a possibilidade de o aluno tomar esse registro como um resumo, por isso as leituras são acompanhadas de uma pergunta que trata de focar sobre o que aquele texto diz para o leitor e assim sucessivamente. Ao final, o texto que resulta das várias leituras sucessivas deve ser apresentado a todos os alunos em uma roda de leitura, podendo, ainda, ser organizado como um ensaio para publicação em obra coletiva da turma. No caso de leitura individual e extensiva, pode ser constituído um portfólio das leituras sucessivas, sendo que deve haver alguns momentos de compartilhamento com os colegas ao longo do tempo destinado à leitura.

\section{Uma experiência de Leitura Cumulativa}

Para tornar o processo acima descrito mais concreto, vamos exemplificá-lo com uma prática de Leitura Cumulativa realizada durante um curso de formação em serviço, no segundo semestre de 2018, com professores de Ensino Fundamental da área de Letras e Pedagogia. Dentre os quinze participantes, doze eram do sexo feminino, a maioria estava na faixa de 23 a 30 anos, com apenas três acima de 30 anos, sendo um destes acima de 40 anos. Todos possuíam experiência profissional, com nove entre três e cinco anos de docência, quatro entre cinco e dez anos, e dois contando mais de uma década. A atividade foi desenvolvida de forma intensiva durante uma única tarde, com cerca de quatro horas de duração.

Por conta desse período bem limitado de tempo, e a circunstância de que a reunião dos alunos em uma turma era efêmera, alguns residindo em cidades diferentes, selecionamos quatro textos curtos para compor a coletânea, com preferência pelo modo poético. Também escolhemos, como tema da coletânea, o reconhecimento do outro e, como elemento formal dos textos, as relações de oposição, como antíteses e paradoxos, aproveitando que o evento ocorreu em período eleitoral, quando o posicionamento político tende a ficar mais evidente e há uma maior preocupação - ou pelo menos atenção - com os problemas sociais. 
O texto básico selecionado foi o poema Solidariedade, de Murilo Mendes (1994), publicado pela primeira vez em 1941. Esse texto foi enviado previamente para a turma com a orientação de que deveriam ler e anotar livremente suas impressões, que poderiam ser desde uma única palavra até alguma associação com outro texto, sem preocupação com a forma do texto, apreciação, interpretação ou qualquer outra constrição. O registro deveria ser trazido para compartilhamento em sala de aula.

No dia do evento, introduzimos a prática com uma atividade de motivação, que também funcionou como forma de apresentação da turma e formação da primeira dupla para a leitura e escrita dos textos, inspirada no vídeo All that we share (em português, Tudo o que compartilhamos), da TV2 Danmark (2017), um canal de televisão dinamarquês. $\mathrm{O}$ vídeo, que tem três minutos de duração, mostra que, a despeito dos rótulos sociais com que nos identificamos, sempre temos algo em comum com o outro. Após assistir o vídeo, a turma foi disposta em formato de $\mathrm{U}$ e fomos construindo grupos dando um passo para o centro. Os grupos eram formados a partir de critérios variados como os casados, os que acreditam em vida além da morte, os que não comem jiló, os que leram Dom Casmurro, os que eram os palhaços da turma, os que foram vítimas de bullying na escola e os que já viveram uma paixão avassaladora. Ao final, os alunos receberam um quarto de folha de papel com o início de uma frase "Eu sou...", que deveria ser completada com uma breve definição de si mesmo e entregue dobrada para um colega que seria o seu parceiro na próxima atividade, devendo ser guardada até o final da prática.

Com os alunos dispostos em dupla (uma delas formada com o professor), foi reforçada brevemente a apresentação do poema Solidariedade, complementando os dados que acompanhavam o texto quando de seu envio. Em seguida, as duplas receberam a tarefa de discutir o poema, com base nas impressões anotadas em casa, tendo como guia a questão: “O poema pode ser lido como uma espécie de definição ou declaração de princípios. Como o poeta se define neste poema?”.

Dado o tempo para discussão e elaboração escrita da resposta, foi apresentado o segundo texto, um fragmento do sermão XVII, Meditation, de John Donne (2011), publicado originalmente em 1624. O fragmento era constituído de um parágrafo com cerca de cinco linhas, iniciado pela frase "Nenhum homem é uma ilha...", conforme tradução em português do original em inglês. Após uma breve apresentação do contexto do fragmento e dados literários e biográficos do autor, os alunos, trocadas as duplas, receberam a instrução de discutir o fragmento em relação ao poema, respondendo: " $O$ 
fragmento pode ser lido como uma alegoria da existência humana. Que recursos o poeta inglês usa para descrever o ser humano? Qual a diferença entre essa definição e aquela que consta no poema de Murilo Mendes?”.

Feito o registro escrito e trocadas mais uma vez as duplas, o texto seguinte foi o curta-metragem Tzafar, dirigido por Nancy Spetsioti (2011). O filme, com apenas 2 min e 40 segundos de duração, narra o encontro entre uma família e o doador de um transplante de medula óssea, primeiro na sala de espera e depois no consultório de um médico. Depois de assistirem o filme por duas vezes seguidas, atendendo pedido de alguns alunos, que queriam entender melhor as cenas e os diálogos, as duplas receberam o seguinte encaminhamento para conduzir a discussão: "O filme encena uma situação que envolve um jovem e uma família. Como você define o comportamento deles? Como a história se relaciona com o poema Solidariedade?".

Dado o tempo de discussão e registro, foram feitas novas duplas e apresentado para discussão o quarto e último texto: a canção Tomara, de Alceu Valença e Rubem Valença Filho (1992), interpretada pelo primeiro. A turma ouviu a canção, que já era conhecida de quase todos, acompanhando a letra que fora entregue em uma folha de papel, com a pergunta: “A canção expressa um desejo. Quais os termos usados pelo cantor para dizer esse desejo? Que relação você estabelece com o poema de Murilo Mendes?"

Depois da discussão e registro escrito, era hora do intervalo para o lanche, que deveria ser de apenas 15 minutos, mas durou cerca de meia hora com alguns alunos já compartilhando informalmente suas leituras com os colegas. No retorno, com as carteiras organizadas em um semicírculo, foi iniciada a plenária de discussão dos textos, com os alunos apresentando as interpretações feitas tanto dos textos individualmente, quanto das relações com o poema de Mendes e com os outros textos.

Inicialmente, a discussão se deu em termos temáticos, com a solidariedade, a identidade do ser humano e o preconceito como aspectos que sintetizavam a necessidade de reconhecimento da existência do outro como ser humano a despeito das diferenças sociais e culturais. Logo, porém, avançou para outros elementos, como as antíteses que se transformam em paradoxo no poema de Mendes, implicando uma definição mais densa do conceito de solidariedade, superando o entendimento comum da doação e aceitação do outro, assim como a relação que havia entre os textos de confirmação e oposição, passando pelos recursos de citação religiosa, metáforas geográficas e economia de 
palavras nas referências sociais e culturais implícitas, entre vários outros que compunham formalmente os textos.

Não é possível sintetizar em poucas linhas a riqueza do debate e os muitos elementos que foram destacados e compartilhados entre os alunos, em que não faltaram referências a outros textos, inferências textuais diversas e contextualizações baseadas nas próprias experiências e conhecimentos. Tudo isso foi registrado em um texto final na forma de um ensaio de não mais que duas páginas que os alunos deveriam produzir em casa e enviar por e-mail para o professor. Esses textos chegaram em velocidades diferentes em um período que foi de um a vinte dias. Apenas um dos alunos não enviou o texto. Não lhe indaguei a razão. Com os catorze textos recebidos, elaborei uma coletânea que compartilhei com todos os autores. O título roubei de um dos ensaios: Preciso do outro para saber quem eu sou.

\section{Para concluir falando de flores}

Ao final da prática de Leitura Cumulativa com professores do Ensino Fundamental, propus aos alunos que refletíssemos sobre o que havíamos acabado de experienciar em termos de letramento literário. Um deles, com muita cerimônia, me ponderou se essa reflexão era mesmo necessária porque para ele o que havíamos feito era algo quase intuitivo em se tratando de ler obras literárias. Acrescentou, ainda, que não entendia como uma prática tão simples poderia se constituir em uma forma de ensino de literatura na escola, nem atender aos desafios que se apresentavam para a necessidade de conciliar as determinações curriculares com o perfil de alunos cada vez menos afeitos à leitura de obra literárias, sobretudo aquelas indicadas pela escola.

Este texto não é a resposta que construímos juntos naquele dia. Para ser aquela resposta, precisaria sintetizar as vozes de todos os alunos que participaram ativamente do debate que se sucedeu após as perguntas do colega, ecoando seus próprios questionamentos sobre o que ensinamos, como ensinamos e porque ensinamos literatura, os pressupostos que assumimos e os caminhos que queremos percorrer como professores de literatura. Vozes que juntamente com a minha falaram de como se tornaram leitores com e contra a escola. Vozes que compartilharam suas experiências de vida e de leitura entrelaçando textos e contextos. Dessa forma, esse texto é apenas um registro aproximado do que pode acontecer em uma sala de aula quando adotamos a leitura cumulativa como 
uma prática de letramento literário. Uma prática de sala de aula que gostaria de saber potencializada, transformada e ampliada por outros professores de literatura na formação do leitor literário na escola.

\section{Referências}

ALL THAT WE SHARE. Vídeo promocional. TV2 Danmark, 2017. Disponível em: https://www.youtube.com/watch?v=1JilaqnPif4 Acesso em 20 jul. 2018.

AZEVEDO, Ricardo. A didatização e a precária divisão de pessoas em faixas etárias: dois fatores no processo de (não) formação de leitores. In: PAIVA, Aparecida et al. (Orgs.). Literatura e Letramento: espaços, suportes e interfaces. Belo Horizonte: Editora Autêntica, 2003, p. 75-86.

COSSON, Rildo; PAULINO, Graça. Letramento literário: para viver a literatura dentro e fora da escola. In: RÖSING, Tânia M.K; ZILBERMAN, Regina (Orgs.). Escola e leitura: velha crise, novas alternativas. São Paulo: Global, 2009, p. 61-79.

DONNE, John. XVII. Meditation. In: DONNE, John. Devotions upon emergent occasions, together with Death's Duel. Project Gutenberg, 2011 [1624] Disponível em: https://www.gutenberg.org/files/23772/23772-h/23772-h.htm Acesso em 10 jan. 2014.

EVEN-ZOHAR, Itamar. Polisistemas de cultura. Tel Aviv: Universidad de Tel Aviv, 2017. Disponível em: https://www.tau.ac.il/ itamarez/works/papers/ trabajos/ polisistemas de cultura.htm Acesso em: 20 jun. 2018.

FREITAS, Eduardo; SANTOS, Maria de Lourdes L. Hábitos de Leitura em PortugalInquérito Sociológico. Lisboa: Publicações Dom Quixote, 1992.

HUTCHEON, Linda. Uma teoria da paródia. Lisboa: Edições 70, 1989.

MANGUEL, Alberto. Uma história da leitura. São Paulo: Companhia das Letras, 1997.

MENDES, Murilo. Poesia completa e prosa. Rio de janeiro: Editora Nova Aguilar, 1994 [1941].

NIKOLAJEVA, Maria. Literacy, competence and meaning-making: a human sciences approach. Cambridge Journal of Education, v. 40, n. 2, p. 145-159, 2010. Disponível em: http://dx.doi.org/10.1080/0305764X.2010.481258 Acesso em: 10 fev. 2016.

OLIVEIRA, Vanderléia da S. Historiografia, cânone e a formação do professor de literatura: ponderações sobre educação literária. In: OLIVEIRA, Vanderléia da S. (Org.). Educação literária em foco: entre teorias e práticas. Cornélio Procópio, 2008. E-book. Disponível em: http://www.ccp.uenp.edu.br/e-books/uenp/2008-vsoliveiraorgeducacao_literaria.pdf Acesso em 12 jan. 2016.

ROSENBLATT, Louise. The reader, the text, the poem: the transactional theory of the literary work. Southern Illinois University, 1994. 
SCHOLES, Robert. Protocolos de leitura. Lisboa: Edições 70, 1991.

SOLÉ, Isabel. Estratégias de Leitura. 6. ed. Porto Alegre: Artmed, 1998.

SPETSIOTI, Nancy. Tzafar. Filme. 2011. Escrito por Katerina Koutsomyti e dirigido por Nancy SPETSIOTI. Elenco: Natalia Dragoumi, Vladimiros Kiriakidis, Nikos Psarras, Chara Tsionga, Waseem Aktar, Georgia Katsikonouri. Produtor: Dimitris Galanopoulos. Disponível em: https://www.youtube.com/watch?v=tW4DC-4cQ50 Acesso em 10 jul. 2018.

STREET, Brian. What's new in new literacy studies? Current Issues in Comparative Education, v. 5, n. 2, p. 1-14, 2003. Disponível em: https://fokt.pw/book-whats-new-innew-literacy-studies-critical-approaches-to-literacy.pdf Acesso em: 20 jun. 2013.

VALENÇA, Alceu; VALENÇA FILHO, Rubem. Tomara. In: VALENÇA, Alceu. 7 desejos. Gravadora EMI, 1992. CD-Rom.

WITTE, Theo; RIJLAARSDAM, Gert; SCHRAM, Dick. An empirically grounded theory of literary development. Teachers' pedagogical content knowledge on literary development in upper secondary education. L1- Educational Studies in Language and Literature, v. 12, p. 1-33, 2012. Disponível em: https://11.publicationarchive.com/publication/1/1372 Acesso em: 22 jun. 2018.

Recebido em 30 de julho de 2020. Aceito em 23 de outubro de 2020. 